\title{
Xylan utilisation promotes adaptation of Bifidobacterium pseudocatenulatum to the human gastrointestinal tract
}

\author{
Yohei Watanabe (iD ${ }^{1 凶}$, Yuki Saito (iD ${ }^{1}$, Taeko Hara (iD ${ }^{1}$, Naoki Tsukuda (iD ${ }^{1}$, Yoshimi Aiyama-Suzuki ${ }^{1}$, Kana Tanigawa-Yahagi (iD) ${ }^{1}$ \\ Takashi Kurakawa ${ }^{1}$, Kaoru Moriyama-Ohara ${ }^{1}$, Satoshi Matsumoto ${ }^{1}$ and Takahiro Matsuki ${ }^{1{ }^{1}}$
}

(c) The Author(s) 2021

Dietary carbohydrates impact the composition of the human gut microbiota. However, the relationship between carbohydrate availability for individual bacteria and their growth in the intestinal environment remains unclear. Here, we show that the availability of long-chain xylans (LCX), one of the most abundant dietary fibres in the human diet, promotes the growth of Bifidobacterium pseudocatenulatum in the adult human gut. Genomic and phenotypic analyses revealed that the availability of LCXderived oligosaccharides is a fundamental feature of $B$. pseudocatenulatum, and that some but not all strains possessing the endo$1,4-\beta$-xylanase (BpXyn10A) gene grow on LCX by cleaving the xylose backbone. The BpXyn10A gene, likely acquired by horizontal transfer, was incorporated into the gene cluster for LCX-derived oligosaccharide utilisation. Co-culturing with xylanolytic Bacteroides spp. demonstrated that LCX-utilising strains are more competitive than LCX non-utilising strains even when LCX-derived oligosaccharides were supplied. In LCX-rich dietary interventions in adult humans, levels of endogenous $B$. pseudocatenulatum increased only when BpXyn10A was detected, indicating that LCX availability is a fitness determinant in the human gut. Our findings highlight the enhanced intestinal adaptability of bifidobacteria via polysaccharide utilisation, and provide a cornerstone for systematic manipulation of the intestinal microbiota through dietary intervention using key enzymes that degrade polysaccharide as biomarkers.

ISME Communications; https://doi.org/10.1038/s43705-021-00066-4

\section{INTRODUCTION}

The human gut microbiota (HGM) and host health are interconnected in various manners [1]. Dietary glycan is a major nutrient for the HGM and significantly affects its composition [2]. One feasible strategy for manipulating the HGM is dietary intervention using indigestible carbohydrates that selectively increase endogenous health-promoting microorganisms [3]. Therefore, understanding glycan metabolic ability of specific HGM species could contribute to establishing a systematic means of manipulating gut microbiota. The HGM possesses a wide variety of carbohydrate-active enzymes (CAZymes) used to break down carbohydrates $[4,5]$, indicating that carbohydrate availability plays an important role in microbiota adaptation to the intestinal environment. Although specific carbohydrate availability influences niche acquisition in the gut of animal models and human infants [6-8], the relationship between carbohydrate availability for individual types of bacteria and their growth remains obscure in the adult human gut, the complex bacterial composition of which widely varies among individuals [9].

Bifidobacteria, which belong to the phylum Actinobacteria, represent one of the core constituents of the HGM [10]. The genus Bifidobacterium is characterised by an abundance of genes related to carbohydrate metabolism [11]; thus, glycan metabolism is thought to be important for their adaptation to the intestinal environment [12]. Beyond some uncharacterised species such as B. pseudocatenulatum, glycan availability of the major HGM bifidobacterial species has been actively investigated. Infant-dominant taxa (e.g., $B$. breve, $B$. bifidum and $B$. longum subsp. infantis) can utilise human milk oligosaccharides (HMO) [13-15], whereas adult-dominant taxa (e.g., $B$. adolescentis and $B$. longum subsp. longum) can utilise plantderived polysaccharides, including starch and the degradation products of long-chain xylans (LCX) $[16,17]$.

LCX are primary components of various plant cell walls, and are the typical indigestible polysaccharides found in the human diet [18]. LCX consists of a $\beta-1,4$-bonded xylose backbone with decorations such as arabinose. In the HGM, a limited number of species of Bacteroidetes and Firmicutes have been known to hydrolyse LCX [19], and the respective degradation mechanisms have been elucidated in detail $[20,21]$. Endo-1,4- $\beta$-xylanase, belonging to the glycoside hydrolase $(\mathrm{GH}) 10$ family, is a key enzyme that extracellularly cleaves the xylose backbone of LCX, which allows oligosaccharide transporters to take up degradation products such as xylooligosaccharides (XOS) [20, 21]. Parts of short-chain oligosaccharides are released during this process into the extracellular milieu, where they are metabolised by other intestinal bacteria [20, 22]. Therefore, a food web of LCX degradation functions in the human gut, and HGM species with endo-1,4- $\beta$-xylanase are generally classified as primary degraders that metabolise LCX and secondary consumers that can only metabolise LCX degradation products.

Bifidobacteria are considered secondary LCX consumers because a strain that can cleave the xylose backbone has not

${ }^{1}$ Yakult Central Institute, Kunitachi, Tokyo, Japan. ${ }^{\circledR}$ email: yohei-watanabe@yakult.co.jp; takahiro-matsuki@yakult.co.jp 
been identified, but several strains can utilise LCX-derived oligosaccharides $[22,23]$. However, in this study, we found that some strains of $B$. pseudocatenulatum, an adult-dominant species $[10,24,25]$ whose carbohydrate utilisation has not been thoroughly investigated, possess endo-1,4- $\beta$-xylanase and could be primary degraders of LCX. Our data revealed the genetic background and ecological significance of a previously overlooked phenotype of bifidobacteria. Furthermore, we confirmed via dietary intervention that LCX availability affects the growth of $B$. pseudocatenulatum in the adult human intestine.

\section{MATERIALS AND METHODS \\ Genome sequencing}

We sequenced the genomes of 35 strains of B. pseudocatenulatum (Supplementary Table S1). These strains were isolated at the Yakult Central Institute and the species were identified based on the 16S rRNA gene sequence analysis. These strains have been isolated in the course of various studies over the past few decades, including many studies on infants and adults. B. pseudocatenulatum cultures were anaerobically incubated in modified Gifu anaerobic medium (Nissui Pharmaceutical, Tokyo, Japan) supplemented with lactose and glucose (both $0.5 \% \mathrm{wt} / \mathrm{vol}$ ) at $37^{\circ} \mathrm{C}$ for $16 \mathrm{~h}$. These culture conditions were applied throughout the study unless stated otherwise. The detailed procedures for genomic DNA extraction, library preparation for MiSeq (lllumina, San Diego, CA, USA), MinION (Oxford Nanopore Technologies, Oxford, UK) and PacBio RS2 (Pacific Biosciences, Menlo Park, CA, USA), and sequencing are described in the Supplementary Methods.

\section{Genome assembly, gene prediction and pangenome analysis} We used Unicycler [26] with default parameters for both short-read and hybrid assembly, and Prokka [27] with default parameters for annotating the reconstructed genomes and those downloaded from the RefSeq database. The annotated genomes were then processed with Roary [28] with a default gene identity cut-off parameter of $95 \%$ for species level pangenome analysis. A representative sequence from each gene cluster was translated into a protein sequence, and CAZymes were identified using the dbCAN2 server [29]. Proteins were considered CAZymes if they were identified using HMMER, DIAMOND and Hotpep with default parameters. We then built a CAZyme gene distribution matrix (Supplementary Table S2) based on the gene presence-absence table determined using Roary.

\section{Carbohydrate utilisation assays}

Strains of $B$. pseudocatenulatum were cultured until they reached the exponential phase, centrifuged, and then, the resulting pellets were suspended to an $\mathrm{OD}_{600}$ of 0.2 in modified peptone yeast extract (PY) medium (100 mM PIPES, $\mathrm{pH}$ 6.7, $2 \mathrm{~g} / \mathrm{L}$ peptone, $2 \mathrm{~g} / \mathrm{L}$ BBL trypticase peptone, $2 \mathrm{~g} / \mathrm{L}$ bacto-yeast extract, $8 \mathrm{mg} / \mathrm{L} \mathrm{CaCl}, 19.2 \mathrm{mg} / \mathrm{L} \mathrm{MgSO}{ }_{4} \cdot 7 \mathrm{H}_{2} \mathrm{O}$, $80 \mathrm{mg} / \mathrm{L} \mathrm{NaCl}, 4.9 \mathrm{mg} / \mathrm{L}$ hemin, $0.5 \mathrm{~g} / \mathrm{L}$ L-cysteine hydrochloride and 100 $\mathrm{ng} / \mathrm{L}$ vitamin $\mathrm{K} 1)$. These suspension cultures were inoculated ( $1 \% \mathrm{vol} / \mathrm{vol})$ into modified PY medium supplemented with $0.5 \%$ (wt/vol) XOS (XyloOligo95P, B Food Science, Aichi, Japan) (PY-XOS), wheat arabinoxylan (Megazyme, Bray, Ireland) (PY-AX) or beechwood xylan (Sigma-Aldrich, Darmstadt, Germany) (PY-XY) and covered with sterile mineral oil $(50 \mu \mathrm{L})$ to prevent evaporation. Growth was monitored anaerobically by measuring the $\mathrm{OD}_{600}$ using a PowerWave 340 plate reader (BioTek, Winooski, VT, USA) every $30 \mathrm{~min}$ in an anaerobic chamber for $48 \mathrm{~h}$. The organic acids produced in PY-XY were analysed using high-pressure liquid chromatography as described [8].

\section{Cloning, expression and purification of recombinant BpXyn10A}

The GH10 domain of the BpXyn10A gene was amplified by PCR using the primers xynA-GH-F (5'-CATCATCATCATCATGCGGAAGGCGACGCCGTA-3') and $\quad x y n A-G H-R \quad\left(5^{\prime}\right.$-AGCAGAGATTACCTAATCCTTGAATGCGTTCATGC-3'), with the genomic DNA of YIT 11027 as a template. A linearised vector was synthesised by PCR using primers pColdll-F (5'-GTAATCTCTGCTTA AAAGCACAGAATCTA-3') and pColdII-R (5'-ATGATGATGATGATGATGCAC TाTGT-3'), and the pColdll vector (Takara Bio, Otsu, Japan) as a template. These fragments were ligated using In-Fusion HD Cloning Kits (Takara Bio, Otsu, Japan), resulting in pColdll-xynA. Escherichia coli BL21 was transformed with pColdll-xynA and cultured to express recombinant
$B p X y n 10 A$ as described by the manufacturer. Bacterial cells were harvested by centrifugation and lysed with B-PER Bacterial Cell Lysis Reagent (Thermo Fisher Scientific, Waltham, MA, USA) containing lysozyme at 100 $\mu \mathrm{g} / \mathrm{mL}$ and $10 \mathrm{U} / \mathrm{mL}$ of DNase I. Recombinant BpXyn10A was further purified using Ni-NTA Spin Column (Qiagen, Hilden, Germany) and analysed by SDS-PAGE.

\section{Endo-xylanase activity assay}

B. pseudocatenulatum YIT 11027, YIT 11952 and YIT $4072^{\top}$ cells were grown anaerobically in PY-AX or PY-XOS medium for $16 \mathrm{~h}$. Cultures $(1.5 \mathrm{~mL})$ were centrifuged (8000 $\mathrm{g}$ for $2 \mathrm{~min}$ at room temperature); then, supernatants were sterilised by passage through a $0.22-\mu \mathrm{m}$ filter. Pelleted cells were washed with modified PY medium and resuspended in $1.5 \mathrm{~mL}$ of the same medium. The endo-xylanase activity of the supernatant and the cell fractions were assayed using Xylanase Assay kits (XylX6 method) (Megazyme, Bray, Ireland) as described by the manufacturer. According to the manufacturer, this kit is designed to specifically detect only endoxylanase activity, and not xylosidase or exo-xylanase enzyme activity.

\section{Purified BpXyn10A-added culture}

B. pseudocatenulatum YIT $4072^{\top}$ and Ba. ovatus YIT $6161^{\top}$ cells were cultured anaerobically until they reached the exponential phase. Thereafter, cultures $(200 \mu \mathrm{L})$ were centrifuged $(8000 \times g$ for $2 \mathrm{~min}$ at room temperature), then pelleted cells were resuspended in modified PY medium $(500 \mu \mathrm{L})$, and inoculated $(1 \% \mathrm{vol} / \mathrm{vol})$ into PY-AX medium supplemented with $0,10,100$ and $1000 \mathrm{ng} / \mathrm{mL}$ purified recombinant BpXyn10A. Growth was monitored anaerobically by measuring the $\mathrm{OD}_{600}$ using the PowerWave 340 plate reader.

\section{RNA-seq analysis}

B. pseudocatenulatum YIT 11952 was cultured in modified PY medium supplemented with $0.5 \%$ (wt/vol) lactose, xylose, XOS, beechwood xylan or arabinoxylan and harvested at mid- to late-log phase. The detailed procedures for total RNA extraction, rRNA removal and sequencing using MiSeq are described in the Supplementary Methods. We obtained a total of 23 million paired-end reads. Low-quality bases (average quality $<30$ ) were trimmed off at the $3^{\prime}$, and the resulting reads with $\mathrm{N}$ bases, or $<70 \mathrm{bp}$ long, were filtered out using cutadapt [30]. Ribosomal RNA reads were removed using SortMeRNA [31]. Filtered reads were then mapped to the complete genome sequence of $B$. pseudocatenulatum YIT 11952 using Bowtie2 [32], and read counts of each gene were determined with featureCounts [33]. The expression levels of each gene were quantified as transcripts per million calculated using Microsoft Excel 2013.

\section{Batch co-cultures of $B$. pseudocatenulatum and $B a$. ovatus}

The 36 strains of $B$. pseudocatenulatum and $B a$. ovatus YIT $6161^{\top}$ were separately grown before co-culture. Cells harvested at the mid- to late-log phase were resuspended in modified PY medium adjusted to an $\mathrm{OD}_{600}$ of 0.2 (B. pseudocatenulatum strains; equivalent to $1 \times 10^{8.4-9.0}$ cells $/ \mathrm{mL}$ ) or 0.02 (Ba. ovatus, equivalent to $1 \times 10^{8.7-9.0}$ cells $/ \mathrm{mL}$ ) so that the numbers of cells were similar. Equal amounts of each suspension were inoculated at $2 \%$ (vol/vol) into the PY-AX medium. After $48 \mathrm{~h}$ of anaerobic co-culture, DNA was extracted using the beads-phenol method as described above. Each sample was analysed by quantitative PCR using an AB7500 real-time qPCR system (Thermo Fisher Scientific, Waltham, MA, USA) to determine cell numbers with specific primers for $B$. pseudocatenulatum (BiCATg-1: $5^{\prime}$ CGGATGCTCCGACTCCT-3' and BiCATg-2: 5'-CGAAGGCTTGCTCCCGAT-3') [10] and $B a$. ovatus (g-Bfra-f: 5'-ATAGCCTTTCGAAGRAAGAT-3' and $\mathrm{g}$ Bfra-r: 5'-CCAGTATCAACTGCAATTITA-3') [34], respectively.

\section{Co-culture time-series experiment between $B$. pseudocatenulatum and $B$. longum subsp. longum}

B. pseudocatenulatum YIT 11952 and B. longum subsp. longum H11-1 (isolated from an infant) were separately grown before co-culture. Cells harvested at the mid- to late-log phase were resuspended in modified PY medium adjusted to an $\mathrm{OD}_{600}$ of 0.2 . Equal amounts ( $2 \% \mathrm{vol} / \mathrm{vol}$ ) of each suspension were inoculated into $500 \mu \mathrm{L}$ of PY-AX medium. After $0,8,24$ and $48 \mathrm{~h}$ of anaerobic co-culture, DNA was extracted from subsamples $(50 \mu \mathrm{L})$ for quantitative real-time $P C R$ using specific primers for $B$. pseudocatenulatum (BiCATg-1 and BiCATg-2) and B. longum subsp. longum (BiLON-1: 5'TTCCAGTTGATCGCATGGTC-3' and BiLON-2: 5'-GGGAAGCCGTATCTCTACGA$\left.3^{\prime}\right)$ [10] using the ABI PRISM 7500 PCR system to determine cell numbers. 


\section{Cereal intervention}

Experimental design. This study was approved by the ethical committee of the Yakult Central Institute, in accordance with the committee guidelines and the Declaration of Helsinki (2013). This study is registered at UMIN Clinical Trials Registry (number UMIN 000043680). Written informed consent was obtained from 30 Japanese adult participants to participate in this study. Three participants who were prescribed with medications during the experimental period were excluded from data analysis. The experiment was completed by 27 ( 19 males and 8 females) participants aged 28-65 years who consumed $30 \mathrm{~g}$ of All Bran Original wheat bran-rich cereal (Kellogg Japan, Tokyo, Japan) with $180 \mathrm{~mL}$ of Accadi lactose-digested milk (Megmilk Snow Brand, Tokyo, Japan) once in the morning and once in the afternoon daily. According to the manufacturer, $60 \mathrm{~g}$ of cereal provided approximately $6.6 \mathrm{~g}$ of wheat bran arabinoxylan per day. Because almost the entire Japanese population has the genotype for low lactase activity [35], we used $80 \%$ lactose-depleted milk according to the manufacturer to minimise the effect of lactose on the growth of Bifidobacterium independently of cereal consumption. The experiment comprised preintervention (days 1-7), intervention (days 8-14) and post-intervention (days 15-21) periods. Throughout the 21 days of the experiment, the participants were instructed to refrain from consuming fermented milk containing bifidobacteria, prebiotic products and foods rich in LCX, such as other bran-rich cereal, whole grain or brown rice.

Faecal samples were collected on days 4, 7, 11, 14, 18 and 21. To reduce daily individual variations, we averaged the results of individual samples from each period. On days without defecation, faecal samples were collected the next day. If no defecation occurred on days 7,14 or 21 , the previous period was extended until a faecal sample was collected. None of the participants skipped the regime for more than 2 days. Faecal samples collected immediately after defecation were placed in sterile tubes, kept on ice and then stored at $-80^{\circ} \mathrm{C}$. Thereafter, DNA was extracted from ten-fold diluted faecal samples using the beads-phenol method as described above.

Quantitation of B. pseudocatenulatum in faecal samples. B. pseudocatenulatum cells were quantified using real-time PCR with a BiCATg primer that targets the 16S rRNA gene. This primer set has been confirmed to be specific for $B$. pseudocatenulatum and $B$. catenulatum and it does not react non-specifically with other bifidobacteria [10]. Although this primer set detects both $B$. pseudocatenulatum and $B$. catenulatum [10], we regarded the measured value as that of only $B$. pseudocatenulatum because none of the participants had amplicon sequence variants (ASVs) close to $B$. catenulatum in the $16 \mathrm{~S}$ rRNA gene amplicon analysis described below. The PCR mixture $(20 \mu \mathrm{L}$ total volume) contained $1 \times$ TB Green Premix Ex Taq II (Takara Bio, Otsu, Japan), $0.2 \mu \mathrm{M}$ of each primer and $2 \mu \mathrm{L}$ of template DNA. The thermocycling conditions used were $94^{\circ} \mathrm{C}$ for $10 \mathrm{~s}$, followed by 40 cycles of $94^{\circ} \mathrm{C}$ for $20 \mathrm{~s}, 55^{\circ} \mathrm{C}$ for $20 \mathrm{~s}$ and $72^{\circ} \mathrm{C}$ for $50 \mathrm{~s}$, then a meltingcurve programme. Amplification was performed using the ABI PRISM 7500 Real-Time PCR System. For absolute quantification, a standard curve was calculated using a ten-fold dilution series of DNA extracted from the B. pseudocatenulatum strain with BpXyn10A, for which cell numbers were determined. The detection limit for this system was $5.0 \times 10^{4}$ cells $/ g$ faeces.

Quantification of cells with BpXyn10A in faecal samples. The numbers of cells with $B p X y n 10 A$ were quantified by real-time PCR with BpXyn10A genetargeted oligonucleotide primers. To design specific primers, we used the sequences of all BpXyn10A genes and their homologues obtained from an NCBI blastn search, aligned them, and detected the specific region of the $B p X y n 10 A$ gene. Then, we designed pBpXyn10A-F (5'-CGAGAATGC GAACACGTACTTC-3') and pBpXyn10A-R (5'-CTGCTCGGTGTTGTAATCGTT G-3'), which provided a $94 \mathrm{bp}$ amplicon. Using Primer-BLAST [36], we confirmed that there were no non-specific sequences that could be amplified in the sequences registered in the NCBI nr database. Furthermore, we performed PCR using DNA from the B. pseudocatenulatum 35 strains used in our study, and confirmed that specific amplification products were obtained only from strains with the BpXyn10A gene. The PCR mixture $(20 \mu \mathrm{L}$ total volume) contained $1 \times$ TB Green Premix Ex Taq II (Takara Bio, Otsu, Japan), $0.4 \mu \mathrm{M}$ of each primer and $2 \mu \mathrm{L}$ of template DNA. The thermocycling conditions used were $95^{\circ} \mathrm{C}$ for $30 \mathrm{~s}$, followed by 40 cycles of $95^{\circ} \mathrm{C}$ for $5 \mathrm{~s}$ and $60^{\circ} \mathrm{C}$ for $34 \mathrm{~s}$, and a melting-curve programme. Amplification was performed using the ABI PRISM 7500 Real-Time PCR System.

$16 \mathrm{~S}$ rRNA gene amplicon analysis. The V1-2 regions of the 16S rRNA gene were amplified. Primer sequence, PCR conditions and details on library preparation are described in the Supplementary Methods. Pooled amplicons were sequenced using the MiSeq platform with the MiSeq reagent kit v2 500 cycle. Obtained reads were analysed using the QIIME22020.8 platform [37]. Briefly, the sequence data were denoised using DADA2, and the resulting ASVs were assigned taxonomy in QIIME2 using the SILVA138 database. Alpha-diversity (observed features, faith pd and Shannon_index) and beta-diversity (unweighted UniFrac) were analysed using QIIME2. Homology of the ASVs was also analysed using vsearch with the 16S RefSeq nucleotide sequence records to determine the closest species. To analyse species level trends, we grouped ASVs with $>97 \%$ homology to closely related species as a single species. No ASVs were more closely related to $B$. catenulatum than to $B$. pseudocatenulatum.

\section{Statistics}

Data were statistically analysed using GraphPad Prism 7.0 (GraphPad Software, San Diego, CA, USA). Average CAZyme gene copy numbers of each species in the genome, amounts of organic acids produced in PY-XY medium and numbers of cells with and without BpXyn10A in the coculture experiments were compared using Mann-Whitney $U$ tests. The effects of the presence or absence of Bacteroides species on the growth of $B$. pseudocatenulatum in co-culture experiments, and the increase or decrease of each bacterial species in the cereal intervention study were verified using Wilcoxon signed-rank tests.

\section{RESULTS}

\section{Composition of B. pseudocatenulatum CAZymes}

To understand the characteristics of carbohydrate utilisation of $B$. pseudocatenulatum within the genus Bifidobacterium, we determined draft or complete genomes of 35 isolates of this species (Supplementary Table S1). We then integrated these genomes with 451 publicly available genomes of the major HGM bifidobacteria and compared repertoires of CAZyme genes (Fig. 1 and Supplementary Table S2). We calculated the average number of gene copies for each species and identified ten CAZyme genes that were characteristically abundant in B. pseudocatenulatum (Fig. 1). Five of them contained enzymes that were involved in bacterial xylan degradation [38]. Among these, the following three $\mathrm{GH}$ families contained enzymes that degrade the xylose backbone of XOS in bifidobacteria: GH43 (xylosidase) [39], GH8 (exooligoxylanase) [40] and GH120 (xylosidase) [41]. The two remaining $\mathrm{GH}$ families (GH10 and $\mathrm{GH} 146)$ have not been verified in bifidobacteria; however, GH10 reportedly contains endo-1,4- $\beta$ xylanase, which is a key enzyme for LCX degradation in HGM xylanolytic species [42]. Therefore, the availability of oligosaccharides derived from LCX and LCX assimilation might be characteristic phenotypes of $B$. pseudocatenulatum. Conversely, genes encoding CAZymes for HMO utilisation [43] such as $\mathrm{GH} 29$ and GH95 (fucosidase), GH33 (sialidase) and GH112 (galacto-N-biose/ lacto-N-biose I phosphorylase) were detected in only a few $B$. pseudocatenulatum strains. These data suggest that $B$. pseudocatenulatum has adapted to the environment of the adult human gut, especially those with a diet rich in LCX.

\section{LCX-related carbohydrate utilisation by $B$. pseudocatenulatum} We examined the availability of LCX-related carbohydrates in 35 isolates and the type strain of $B$. pseudocatenulatum. All 36 strains grew on a mixture of short-chain XOS (degree of polymerisation, $2-4)$, indicating that XOS availability is a universal feature of this species (Fig. 2a). Of the 36 strains, 12 could utilise arabinoxylan, a representative LCX (Fig. 2b). Furthermore, the strains that utilised arabinoxylan grew on xylan (Fig. 2c). Although the turbidity of several other strains gradually increased, only these 12 strains produced substantial amounts of organic acids (Fig. 2c), indicating that xylan availability was clearly distinguished between these 12 and other strains. The availability of LCX was completely consistent with the presence of the GH10 gene (Fig. 2d). The GH10 proteins detected in our isolates had $99-100 \%$ amino acid sequence similarity among each other. To confirm the enzymatic activity, we prepared a recombinant $\mathrm{GH} 10$ domain protein and mixed it with three types of LCX. Because of the accumulation of 


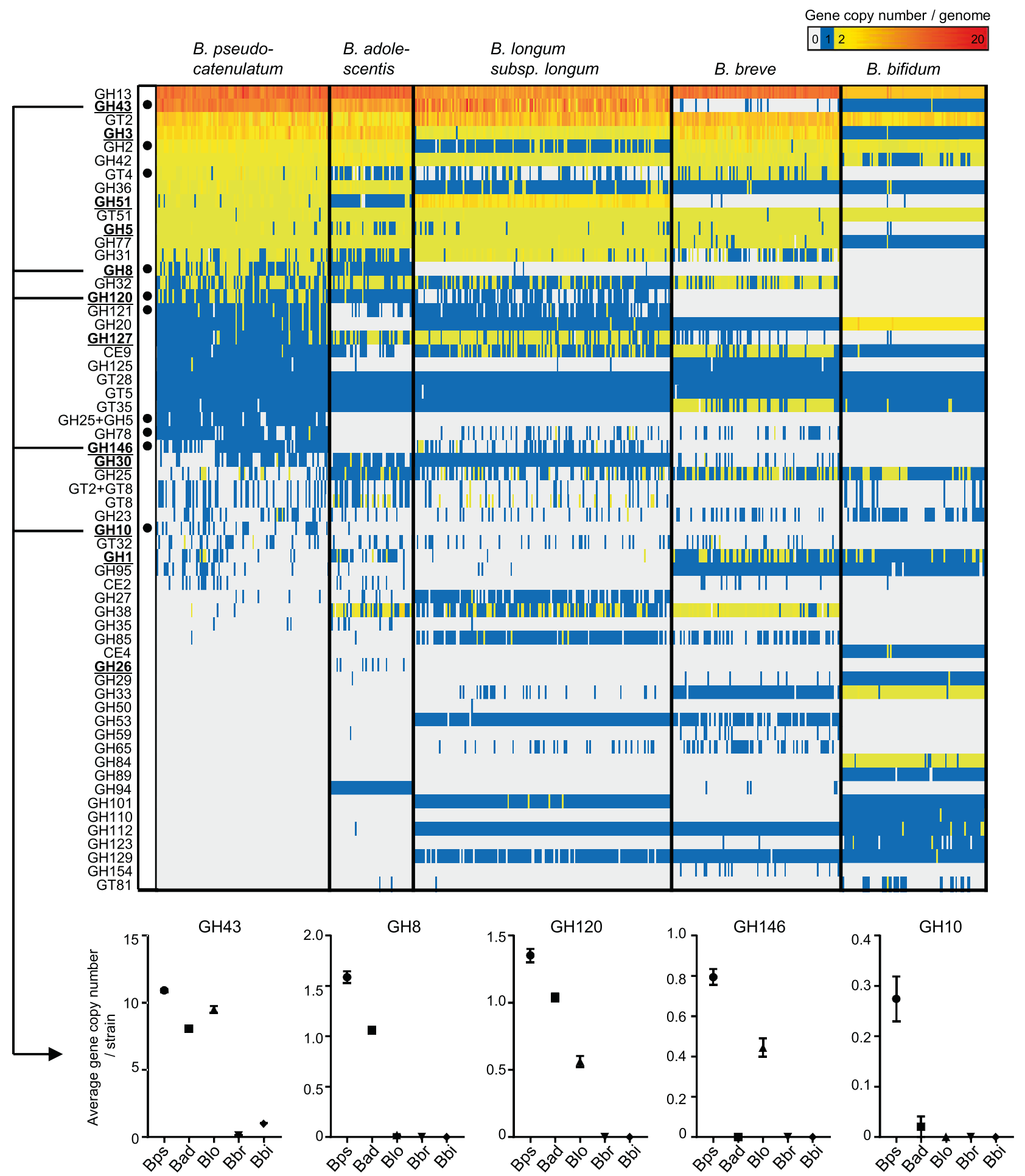

Fig. 1 Comparative analysis of CAZyme composition among human-resident bifidobacteria. The heatmap shows copy numbers of the CAZyme gene per genome of 486 strains belonging to B. pseudocatenulatum (102 strains), B. adolescentis (49 strains), B. longum subspecies longum (151 strains), B. breve (99 strains) and B. bifidum (85 strains). Each column represents a strain, and each row represents a CAZyme gene detected from at least one strain in this data set. CAZymes marked in bold and underlined represent xylan degradation-related CAZymes. Black circles indicate the gene with the highest average copy number in B. pseudocatenulatum, among other species (Mann-Whitney $U$ test; $P$ $<0.01$ ). Five of these CAZymes were also shown in separated plots with mean \pm standard error. See Supplementary Table S2 for the actual copy number of each CAZyme gene.

short-chain oligosaccharides (Fig. 2e), and because all known enzymatic activities in the GH10 family are endo-type (http://www. cazy.org/GH10.html), the enzyme was identified as endo-1,4- $\beta$ xylanase, which we named BpXyn10A. This enzyme contains a
GH10 catalytic domain, a carbohydrate-binding module family 9 (CBM9) domain and transmembrane regions (Fig. 2f). Since transmembrane regions were detected, BpXyn10A was expected to be associated with the membrane, and localise to the cell 

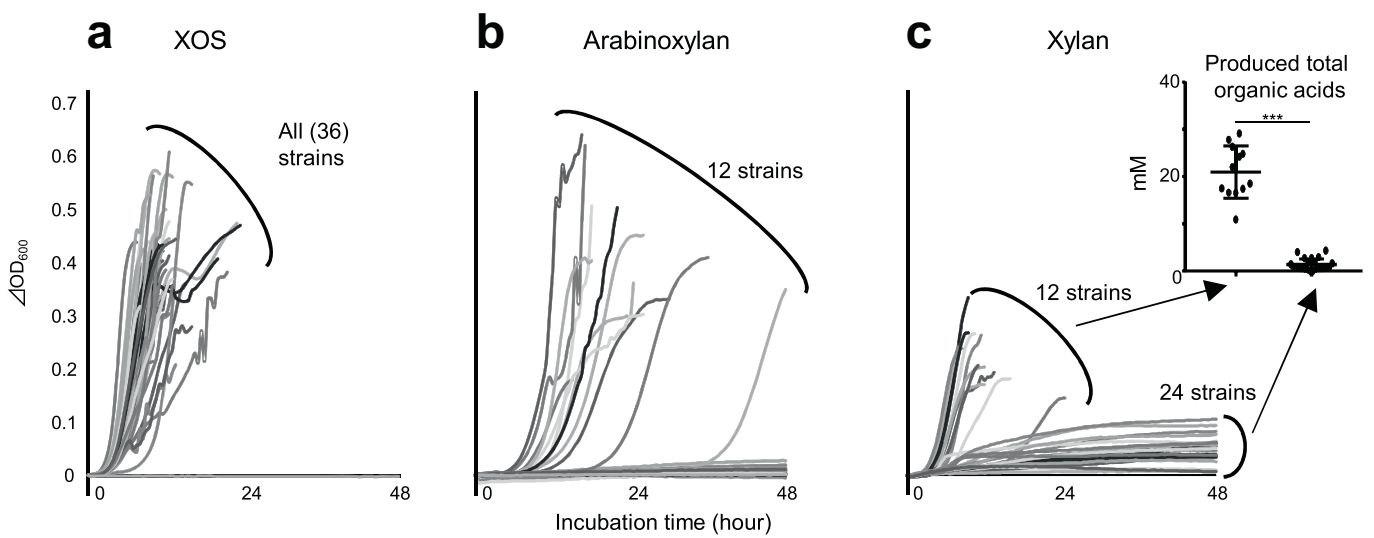

d

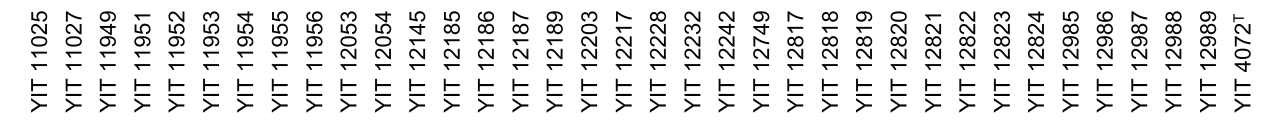

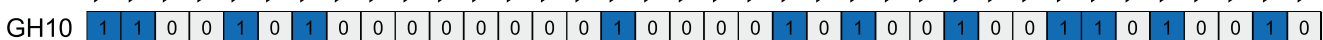

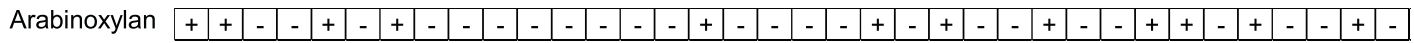

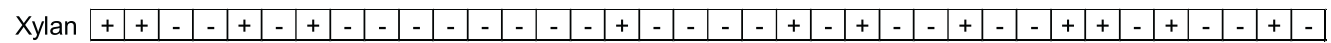

e

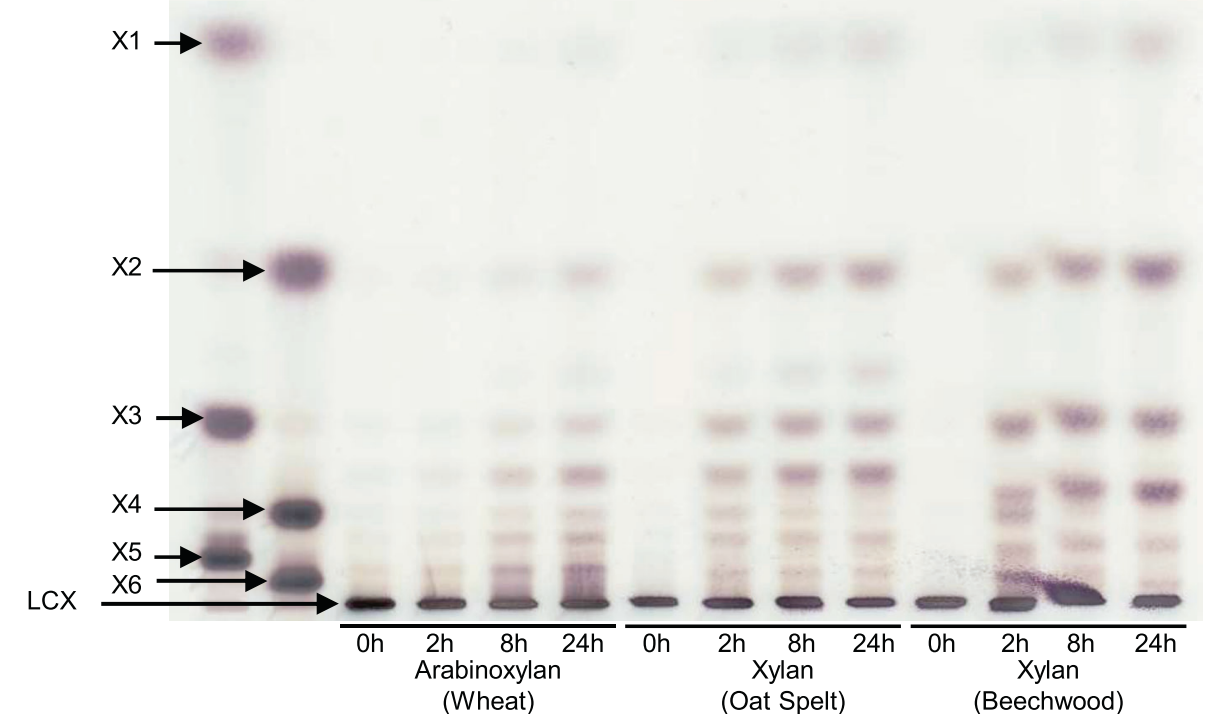

f
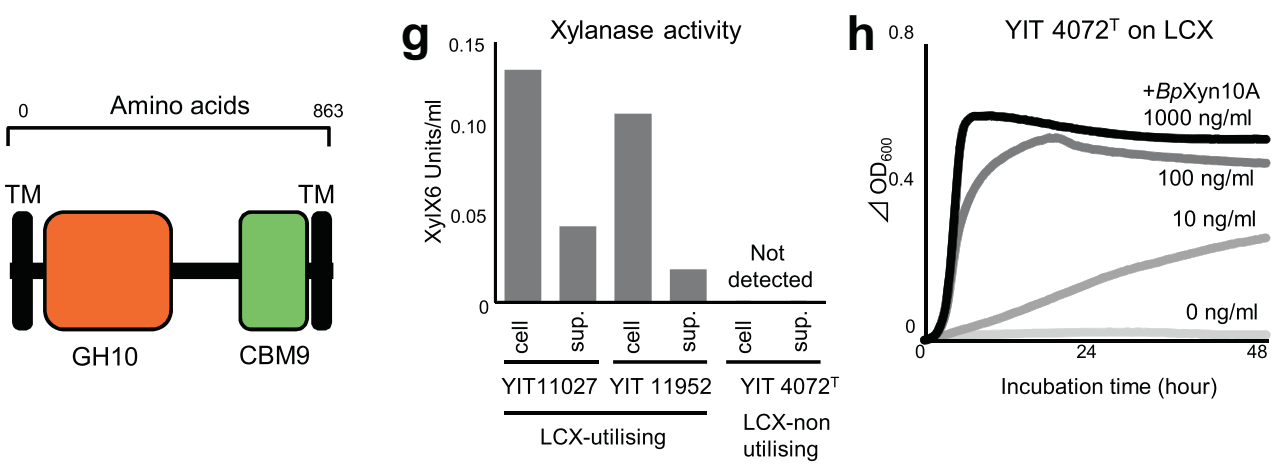

surface, similar to other HGM xylanolytic species [20, 21]. However, enzyme activity was detected not only on the cell surface but also in the filtered culture supernatant (Fig. 2g). Adding purified recombinant $B p X y n 10 A$ allowed a non-LCX-utilising strain to grow on LCX (Fig. 2h). Therefore, LCX availability is determined by the $B p X y n 10 A$ gene in the B. pseudocatenulatum genome.

\section{Genetic background of LCX utilisation}

We analysed the genomic locus of the BpXyn10A gene to clarify the genetic background of the LCX-utilising strain. The BpXyn10A gene in all LCX-utilising $B$. pseudocatenulatum strains was located in the arabinoxylan-hydrolysate (AXH) utilisation gene cluster II, which is one of the gene clusters the expression of which is induced by AXH [39] 
Fig. 2 LCX utilisation by the strains that possess a GH10 (BpXyn10A) gene. Growth curves of our isolates and the type strain in the medium supplemented with XOS (a), arabinoxylan (b) or xylan (c) as the only carbohydrate source. In panel c, total organic acid production in the supernatant is also shown. ${ }^{* * * P}$ value of Mann-Whitney $U$ test $<0.001$. d The association between the presence/absence of predicted GH10 gene and growth phenotype. + indicates an exponential increase in turbidity of $>0.1$. e Endo-xylanase activity of purified recombinant GH10 analysed using thin-layer chromatography. A sample was collected over time after mixing each substrate, and the enzyme was applied. X1: xylose. X2: xylobiose. X3: xylotriose. X4: xylotetraose. X5: xylopentaose. X6: xylohexaose. $f$ Domain organisation of BpXyn10A identified using dbCAN2 [29] and the PSORT web application (http://psort.hgc.jp/form.html); GH10, catalytic module of glycoside hydrolase 10; CBM9, carbohydrate-binding module 9; TM, transmembrane region. g Localisation of endo-1,4- $\beta$-xylanase activity of the LCX-utilising and non-utilising strains. $\mathbf{h}$ Growth of the non-LCX-utilising strain (YIT $4072^{\top}$ ) in the arabinoxylan medium supplemented with multiple concentrations of purified recombinant BpXyn10A.

a

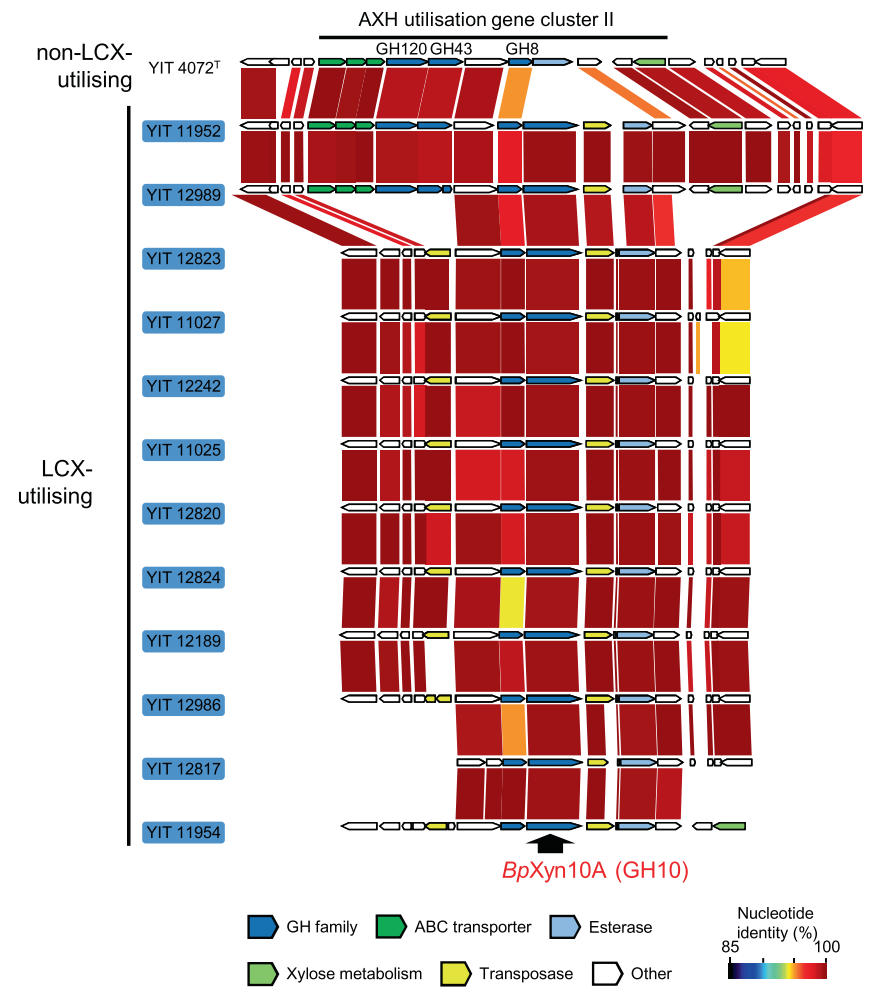

b

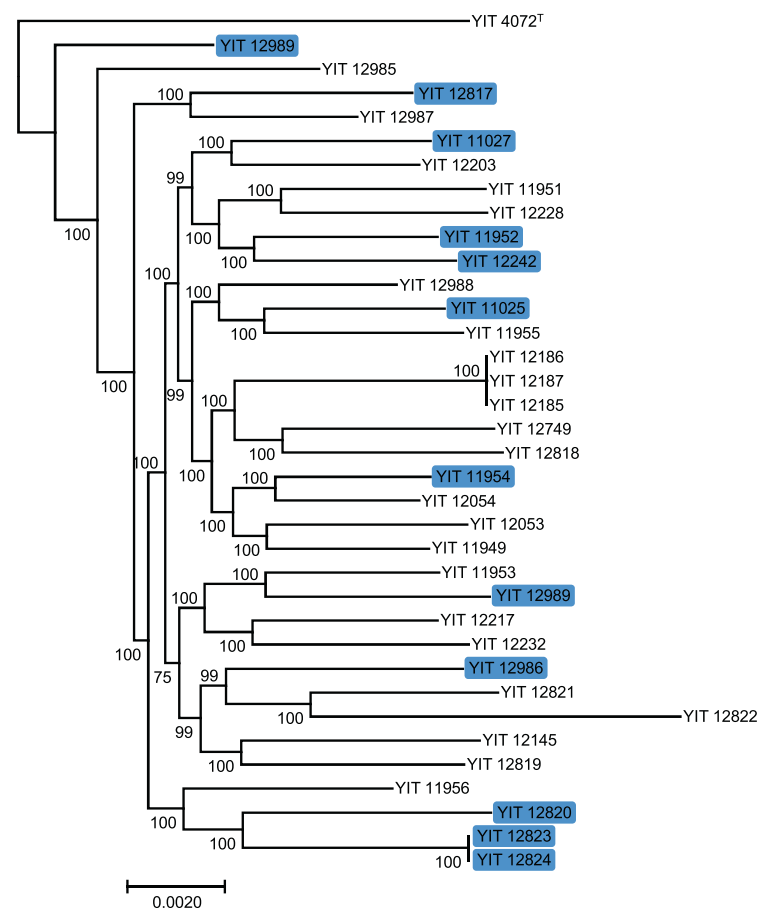

Fig. 3 Genetic locus and strain distribution of BpXyn10A. a The gene arrangement around the BpXyn10A gene. Nucleotide identity of each gene was visualised using GenomeMatcher software [49]. Gene annotation details are also shown in Fig. 4a using the YIT 11952 as an example. b A phylogenetic tree based on the alignment of core genes in 35 isolates and the type strain. Strains with the BpXyn10A gene are shown in blue. Local support values at the branch nodes were computed using the Shimodaira-Hasegawa test with the default parameter settings of fasttree [50].

(Fig. 3a). The BpXyn10A gene was adjacent to the transposase gene in all LCX-utilising strains. These genes were not detected in any other genomic regions of $B$. pseudocatenulatum. Considering that the horizontal transfer of a single transposase gene together with an adjacent gene between bifidobacteria strains in vitro has been confirmed [44], the BpXyn10A gene might have been horizontally transferred along with a transposase from another taxon. A homology search of public databases showed that the BpXyn10A was more homologous to proteins in other species of bifidobacteria (maximum, $86.41 \%$ ) and non-HGM Actinobacteria (maximum, 47.55\%) than those detected in Bacteroidetes (maximum, 32.95\%) and Firmicutes (maximum, 35.29\%) (Supplementary Table S3). These findings indicated that the origin of BpXyn10A is within the phylum Actinobacteria, but not Bacteroidetes or Firmicutes. However, no genomes with both BpXyn10A and transposase genes were found in the database; thus, the acquisition source of these genes remains unclear. In phylogenetic tree analysis, strains with BpXyn10A did not form a single cluster but rather were spread out (Fig. 3b), suggesting that the BpXyn10A gene was not acquired in a single horizontal transfer event in the past, but may have been acquired at multiple occasions from different genetic sources.

\section{Expression control of BpXyn10A}

In order to assess possible transcriptional regulation of the BpXyn10A gene, we performed RNA-seq on the LCX-utilising strain cultured with LCX-associated carbohydrates. The expression of $B p X y n 10 A$ and its surrounding genes was upregulated in the presence of xylose, XOS, xylan and arabinoxylan in B. pseudocatenulatum (Fig. 4a and Supplementary Table S4). A common feature among known HGM xylanolytic bacteria is that intact LCX induces the expression of endo-1,4- $\beta$-xylanase $[20,21]$. The unique feature of $B$. pseudocatenulatum was that xylose, a monosaccharide, also functions as an induction substrate. The expression induced by LCX-associated carbohydrates was similar to that of the AXH utilisation gene cluster II (Fig. 4a), indicating that this cluster acquired the BpXyn10A gene without disrupting its original gene regulation. Furthermore, two other $\mathrm{AXH}$ utilisation gene clusters were upregulated by LCX (Supplementary Fig. S1). Based on the present and previous findings [39], we propose a model for LCX utilisation by $B$. pseudocatenulatum, in which BpXyn10A cleaves the xylan backbone and then, resulting oligosaccharides are taken up and further degraded by the AXH utilisation system (Fig. 4b). 


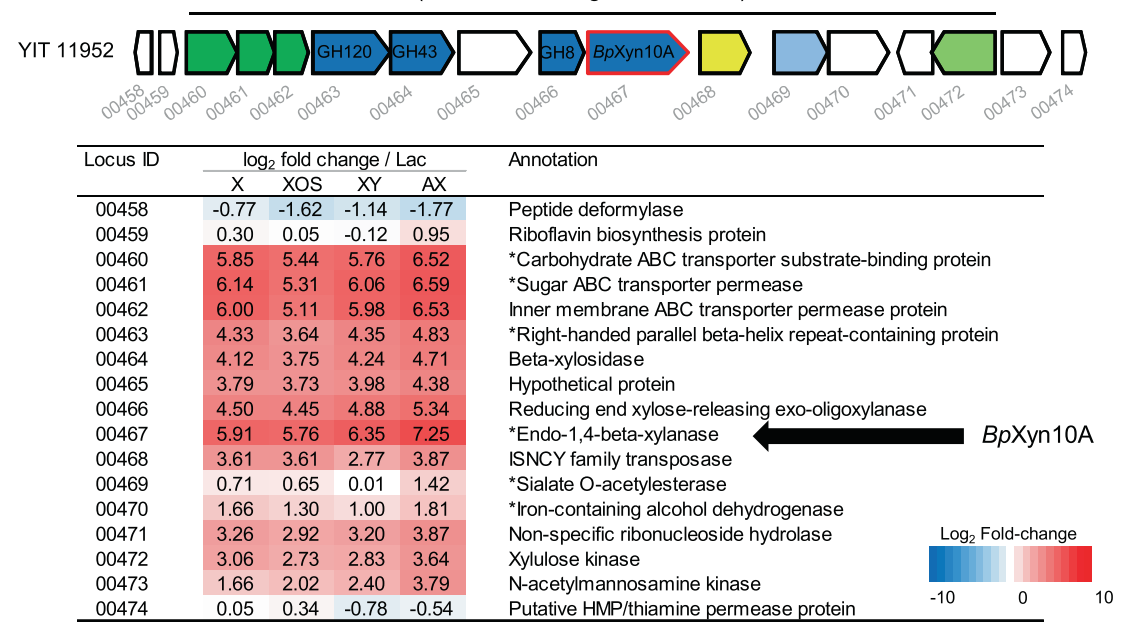

b

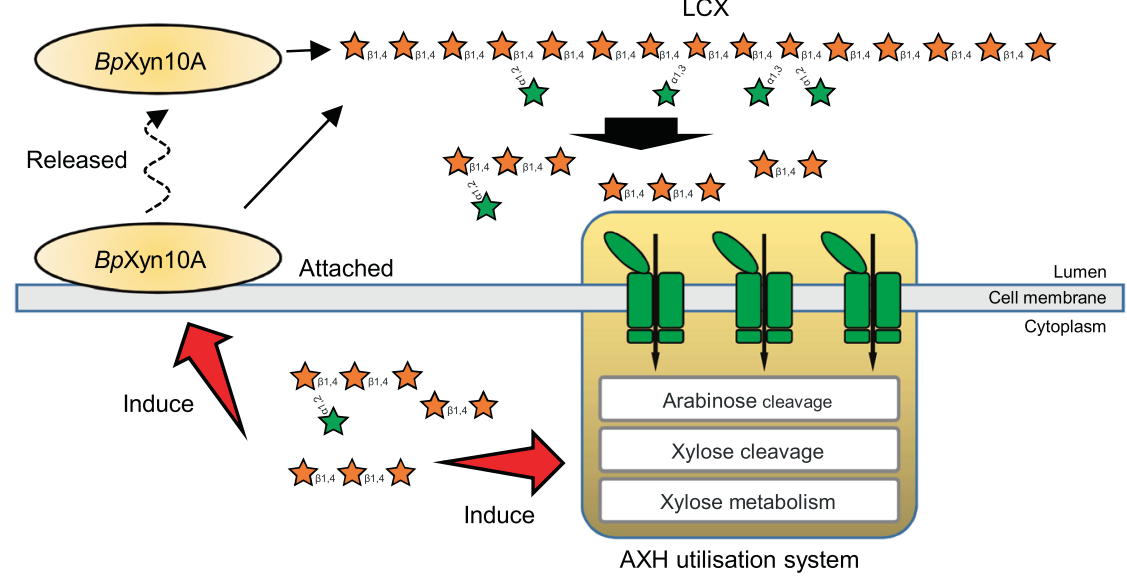

Fig. 4 The LCX utilisation system of B. pseudocatenulatum. a Expression profiles of genes around the BpXyn10A gene from strain YIT 11952. Heatmap depicts $\log _{2}$ fold changes of the expression on xylose (X), XOS, xylan (XY) and arabinoxylan (AX) relative to lactose. Annotation information is from Prokka [27]. Asterisks indicate functional proteins that were not annotated in Prokka, but were found to have $>95 \%$ amino acid homology by Blastp searches against the NCBI nr database. Locus ID YIT11952_xxxxx are abbreviated with the last numbers after the underscore. b LCX utilisation model using arabinoxylan as an example. Initial degradation of LCX occurs by both cell-anchored and extracellularly released BpXyn10A. Degradation products were imported to the cytoplasm and further degraded by the AXH utilisation system as described previously [39]. Imported degradation products induce the expression of the BpXyn10A and AXH utilisation system.

\section{Impact of BpXyn10A on interspecies interaction}

To assess the effect of BpXyn10A on interspecies interactions, we performed co-culture experiments on medium supplemented with arabinoxylan as the only carbohydrate source. Similar to previous findings of non-LCX-utilising Bifidobacterium species [20], the growth of strains without BpXyn10A was stimulated by coculture with Bacteroides ovatus, an established HGM xylanolytic species [20], whereas that of strains with BpXyn10A was not (Fig. 5a). The cell numbers of strains with $B p X y n 10 A$ in co-cultures were higher than those of the strains without BpXyn10A (Fig. 5a), indicating that $B p X y n 10 A$ provided an ecological advantage even in environments where coexisting bacteria supplied breakdown products. In contrast to $B$. pseudocatenulatum, the numbers of $B a$. ovatus cells decreased when co-cultured with $B$. pseudocatenulatum strains with $B p X y n 10 A$ rather than without this enzyme (Fig. 5b). Furthermore, adding purified recombinant BpXyn10A reduced the numbers of $B a$. ovatus cells (Supplementary Fig. S2). Because the expression of xylanase in Bacteroidetes spp. is induced by long-chain XOS but not by short-chain XOS [45], the decreased number of $B a$. ovatus can be explained by a reduced degree of xylose backbone polymerisation by BpXyn10A, resulting in a decreased expression of the xylanase. We then examined whether a strain with BpXyn10A produces a growth substrate for other nonLCX-utilising bifidobacteria. The results of co-culture on arabinoxylan showed that the strain with $B p X y n 10 A$ promoted the growth of $B$. longum subsp. longum strain $\mathrm{H} 11-1$, which utilised XOS but not arabinoxylan (Fig. 5c). Furthermore, we confirmed that the LCX-utilising strain released short-chain oligosaccharides from LCX into the culture supernatant (Supplementary Fig. S3). These results indicate that strains with BpXyn10A promote the growth of other secondary LCX consumers by releasing breakdown products. Therefore, the presence of the BpXyn10A gene in the genome defined whether the $B$. pseudocatenulatum strain would act as a keystone species or a recipient of LCX-derived oligosaccharides, and potentially affected the growth of other direct and indirect LCX-degrading microorganisms in the HGM.

\section{Ecological role of BpXyn10A in the human intestine}

Based on the findings of our co-culture experiments, we speculated that supplementation with LCX would increase the population of $B$. pseudocatenulatum cells with $B p X y n 10 A$ in the human intestine. $B$. pseudocatenulatum has been detected in most 

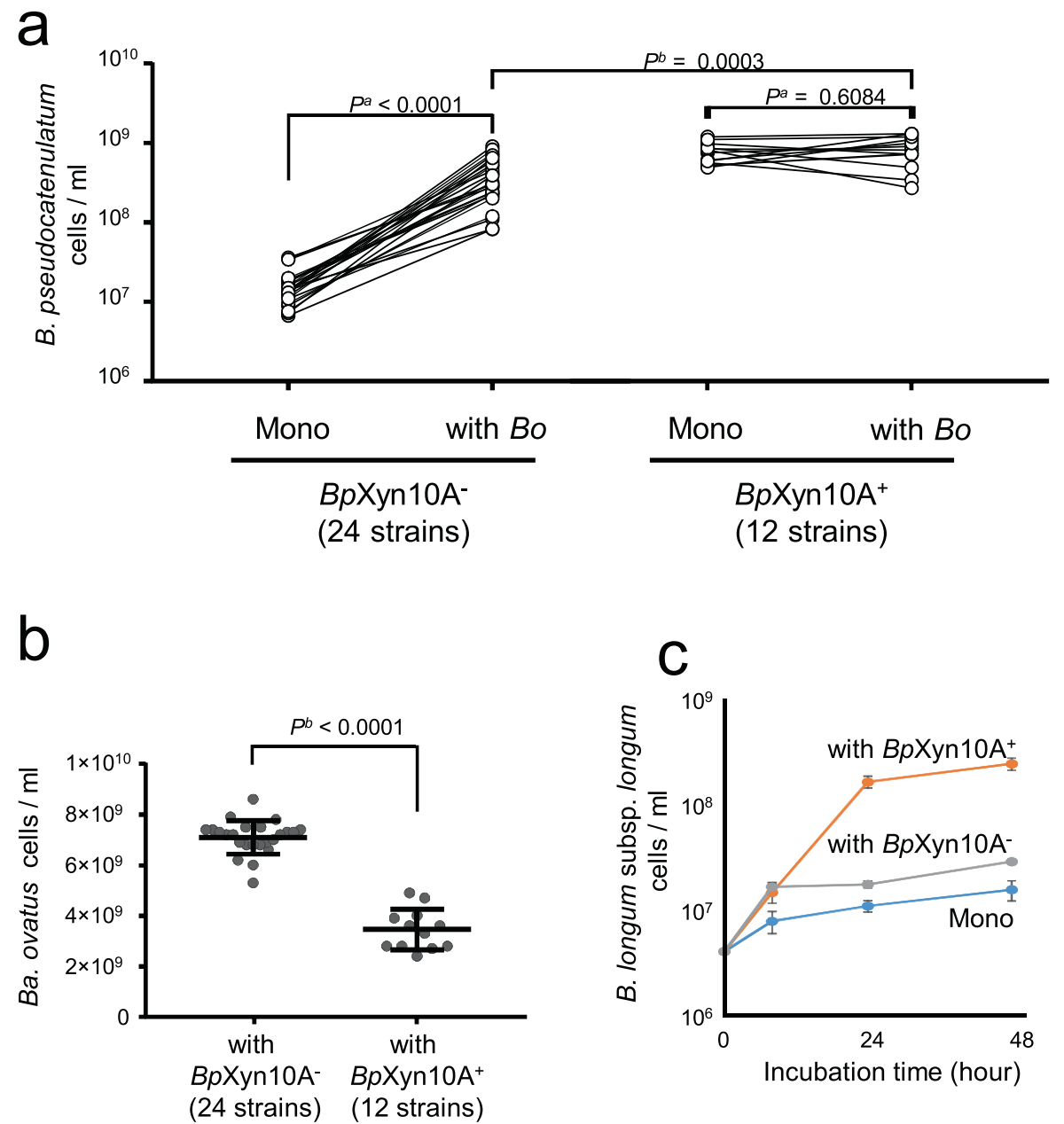

Fig. 5 Co-culture of $B$. pseudocatenulatum and other HGM species in medium with arabinoxylan. a Cell numbers of mono- and co-cultures of $B$. pseudocatenulatum strains with or without the $B p$ Xyn $10 A$ gene. $P^{a}: P$ value of Wilcoxon signed-rank test, $P^{b}: P$ value of Mann-Whitney $U$ test. b Cell numbers of $B a$. ovatus co-cultured with $B$. pseudocatenulatum strains with or without the $B p X y n 10 A$ gene. $P^{b}: P$ value of Mann-Whitney $U$ test. c Cell number of $B$. longum subsp. longum co-cultured with B. pseudocatenulatum strain with (YIT 11952) or without (YIT $4072^{\top}$ ) the BpXyn10A gene. Data are expressed as mean of quadruplicate experiments \pm standard deviation.

Japanese adults $[10,24]$, and about one-third of our isolates from Japanese adults possesses BpXyn10A (Fig. 2d). Therefore, we assumed that some Japanese individuals harbour $B$. pseudocatenulatum cells with BpXyn10A and others harbour those without $B p$ Xyn10A. Under this assumption, we provided Japanese adults with commercially available LCX-rich cereal food made mainly from wheat bran, then compared the behaviour of $B$. pseudocatenulatum cells using qPCR (Fig. 6a). As expected, 10 out of 27 participants $(37 \%)$ possess B. pseudocatenulatum cells with BpXyn10A (BpXyn10A + group), 10 (37\%) possess B. pseudocatenulatum cells without it (BpXyn10A-group) and $7(26 \%)$ possess no detectable $B$. pseudocatenulatum (Bp- group) (Fig. 6b). The number of cells with $B p X y n 10 A$ in the $B p X y n 10 A+$ group ranged from $1 \times 10^{5.9}$ to $1 \times 10^{9.7} / \mathrm{g}$ faeces (Fig. $6 \mathrm{~b}$ ). The number of cells with $B p X y n 10 A$ increased during the intervention in all participants (Fig. 6b). Furthermore, the total number of B. pseudocatenulatum cells (regardless of the presence and absence of $B p X y n 10 A)$ significantly increased during the intervention in the $B p X y n 10 A+$, but not in the BpXyn10A-group (Fig. 6b). These findings indicate that $B p X y n 10 A$ defines the growth potential of $B$. pseudocatenulatum in LCX-rich intestinal environments.

We then applied 16S rRNA gene amplicon analysis to determine the impact of BpXyn10A on the composition of HGM. Alpha- and beta-diversity significantly differed between the three groups
(Fig. 6c, d and Supplementary Fig. S4a). In particular, the $B p X y n 10 A+$ and BpXyn10A- groups differed not only during, but also before the intervention, suggesting that BpXyn10A affected the HGM composition even at the level of LCX supplied in a regular daily diet. The responses of the Bifidobacterium genus to the intervention obviously differed among the three groups, with an increase of relative abundance only in the $B p X y n 10 A+$ group (Fig. 6b and Supplementary Fig. S4b). This mainly resulted from the increase of $B$. pseudocatenulatum, and no changes were evident in other bifidobacterial species such as $B$. longum or $B$. adolescentis (Supplementary Fig. S5). The relative abundance of the representative LCX-utilising genera Bacteroides and Roseburia in the HGM did not significantly increase in either the $B p X y n 10 A+$ or BpXyn10A- groups (Supplementary Fig. S5). In summary, the ability of $B p X y n 10 A$ to promote or inhibit the growth of other bacterial species, such as those found in co-cultures in vitro, was limited in the complex human gut environment. Nevertheless, the results of the $16 \mathrm{~S}$ rRNA gene amplicon analysis showed that $B p$ Xyn10A affected the growth potential of B. pseudocatenulatum.

\section{DISCUSSION}

This study showed that LCX availability is essential to promote adaptation of Bifidobacterium pseudocatenulatum in the adult 
a

LCX-rich cereal 60 g/day

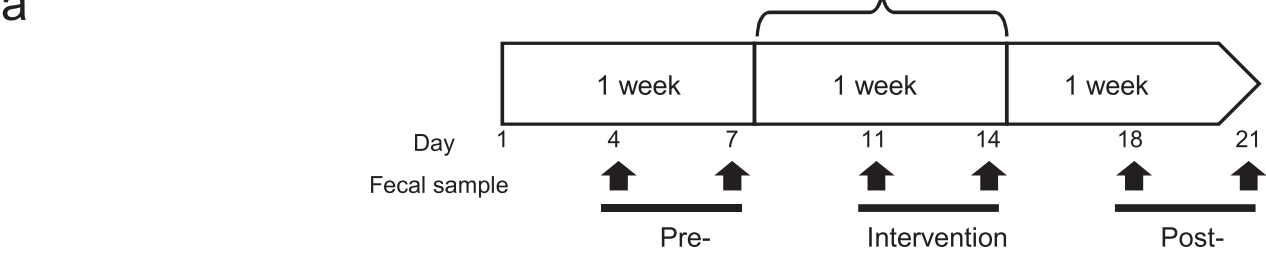

b

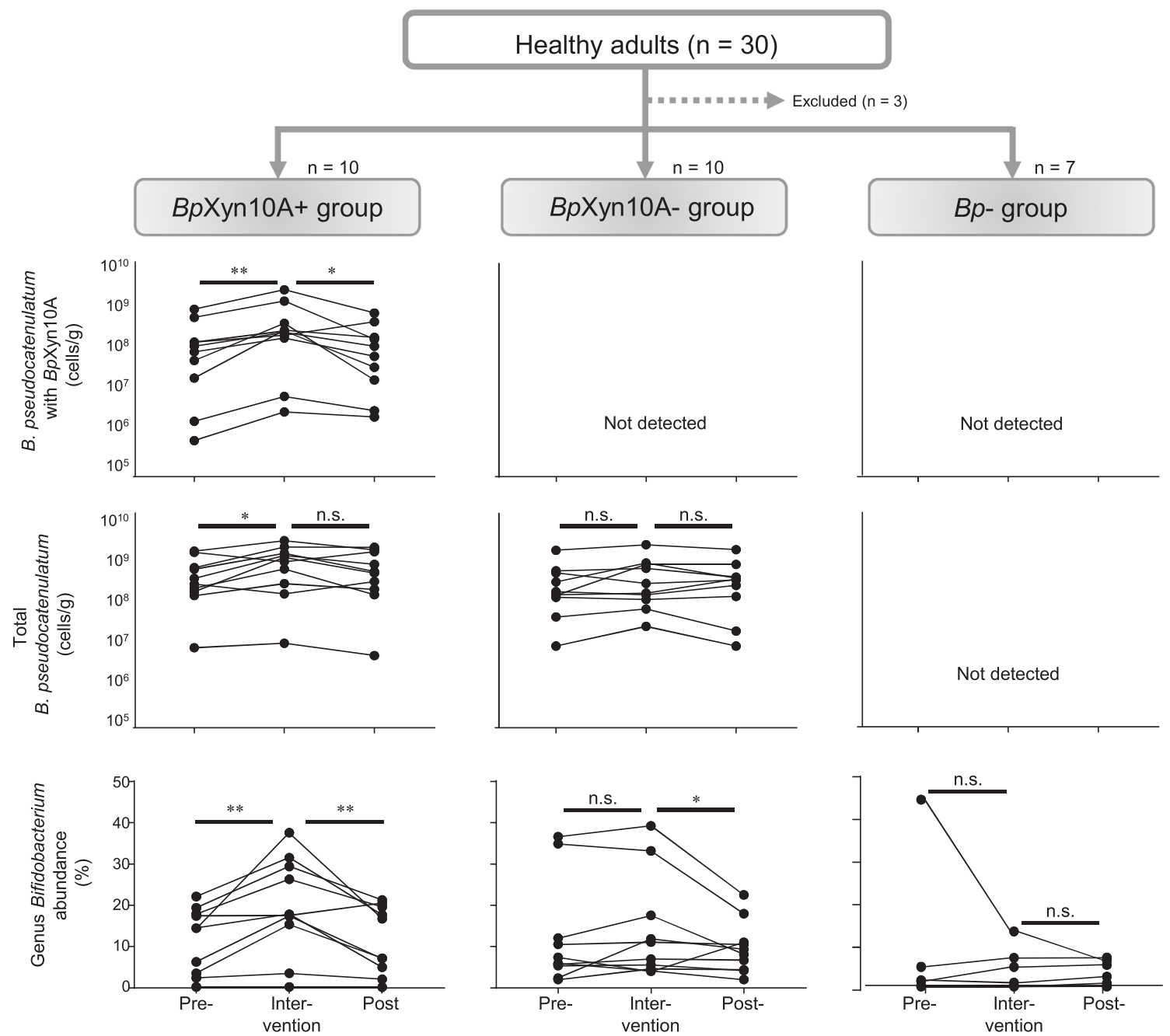

C

\begin{tabular}{|c|c|c|c|c|c|c|c|c|}
\hline \multirow{2}{*}{ Unweighted UniFrac significance } & \multicolumn{3}{|c|}{ All } & \multicolumn{3}{c|}{ Pre- } & \multicolumn{3}{c|}{ Intervention } & \multicolumn{2}{c|}{ Post- } \\
\cline { 2 - 9 } & pseudo-F & p-value & pseudo-F & p-value & pseudo-F & p-value & pseudo-F & p-value \\
\hline BpXyn10A+ vs Bp Xyn10A- & 6.653 & $\mathbf{0 . 0 0 1}$ & 2.082 & $\mathbf{0 . 0 0 2}$ & 2.422 & $\mathbf{0 . 0 0 3}$ & 1.651 & 0.122 \\
\hline
\end{tabular}

d

\begin{tabular}{|c|c|c|c|c|c|c|c|c|c|}
\hline \multirow{2}{*}{$\begin{array}{c}\text { Average } \\
\text { Shannon index }\end{array}$} & \multicolumn{3}{|c|}{ Pre- } & \multicolumn{3}{c|}{ Intervention } & \multicolumn{3}{c|}{ Post- } \\
\cline { 2 - 10 } & $B p$ Xyn10A+ & BpXyn10A- & p-value & BpXyn10A+ & BpXyn10A- & p-value & Bp Xyn10A+ & Bp Xyn10A- & p-value \\
\cline { 2 - 10 } & 5.96 & 6.32 & $\mathbf{0 . 0 4 0}$ & 5.83 & 6.40 & $\mathbf{0 . 0 2 3}$ & 6.01 & 6.55 & $\mathbf{0 . 0 0 5}$ \\
\hline
\end{tabular}

Fig. 6 Effect of the presence or absence of the BpXyn10A gene in the human intestine on the population of $B$. pseudocatenulatum and genus Bifidobacterium during LCX-rich cereal intervention. a Study design. Participants consumed a $60 \mathrm{~g}$ bowl of LCX-rich food per day (see Methods). b B. pseudocatenulatum cells with BpXyn10A and total B. pseudocatenulatum, and relative abundance of genus Bifidobacterium on the participants grouped based on the presence or absence of $B$. pseudocatenulatum and BpXyn10A gene. Cell numbers were determined using the quantitative value of qPCR targeting the BpXyn10A and 16S rRNA genes of $B$. pseudocatenulatum. Relative abundance was obtained from $16 \mathrm{~S}$ rRNA gene amplicon analysis. ${ }^{* *} P$ value of Wilcoxon signed-rank test $<0.01$; ${ }^{*}<0.05$. n.s.: not statistically significant. c PERMANOVA exploring the differences in microbial composition between groups based on unweighted Unifrac distance. $\mathbf{d}$ Comparison of Shannon index between groups. $P$ values of Kruskal-Wallis test are shown. 
human gut. In infants, HMO availability is known to be a key colonisation factor for bifidobacteria [8], and in adults, LCX availability contributes to niche expansion of the representative adult-dominant species $B$. pseudocatenulatum. This finding extends our understanding of the adaptive strategy of bifidobacteria to the human gut environment. In addition, our findings provide new insights into the food web of LCX degradation in HGM.

We showed that bifidobacteria, which are considered secondary LCX consumers, behave as primary degraders if they possess the $B p X y n 10 A$ gene. To the best of our knowledge, the present study is the first to show that HGM organisms other than Bacteroidetes and Firmicutes possess key enzymes for LCX degradation. This leads to the question as to whether LCX metabolism is a characteristic only of $B$. pseudocatenulatum among bifidobacteria. At present, $B$. pseudocatenulatum is the only species expressing biochemically confirmed endo-1,4- $\beta$-xylanase in the Bifidobacterium genus. Conversely, a $B p X y n 10 A$ homologue was also identified in a few strains of other species of HGM Bifidobacterium (Supplementary Table S3). These findings suggested that the availability of LCX by HGM Bifidobacterium may have been overlooked in previous studies.

The BpXyn10A gene was integrated into the AXH utilisation gene cluster II (Figs. 3a and 4a), which contains genes related to the uptake and further degradation of oligosaccharides produced by BpXyn10A, indicating that AXH utilisation gene cluster II has evolved into an LCXutilisation gene cluster. Because the LCX-utilisation gene cluster was induced by xylose or XOS (Fig. 4a), horizontal transfer of the BpXyn10A gene generated an LCX-utilisation gene cluster with the regulatory mechanisms for secondary consumers. Because xylose and XOS are products of BpXyn10A enzymatic activity (Fig. 2e and Supplementary Fig. S3), the LCX-utilisation gene cluster of $B$. pseudocatenulatum can be regarded as having a positive feedback regulation mechanism. This is a feature that is not found in other known LCX-utilisation gene clusters of xylanolytic HGM species, in which intact LCX is the inducible substrate but not low-molecule carbohydrates such as xylose $[21,46,47]$. Having a positive feedback regulation mechanism might explain the obvious increase in $B$. pseudocatenulatum cells with BpXyn10A during the LCX-rich dietary intervention, even though other representative xylanolytic genera in HGM did not significantly increase.

We showed that $B p X y n 10 A$ contributes to increasing numbers of $B$. pseudocatenulatum cells in vitro (Fig. 5) and in the human intestine (Fig. 6). A previous study found that LCX availability is a core fitness determinant in the Bacteroides species in mice fed with a high-plant polysaccharide or purified arabinoxylan diet [7]. These findings indicate that LCX availability is a pivotal feature common to different bacterial species among various host gut environments. Therefore, it is reasonable to assume that there is positive selection pressure for BpXyn10A and that strains with this enzyme will become predominant among the isolates. Nevertheless, strains with BpXyn10A accounts for only $\sim 33 \%$ of our isolates. This discrepancy might be related to the release of $B p X y n 10 A$ into the extracellular milieu, where LCX degradation products can be shared by cells producing the enzyme and secondary consumers. Therefore, when an intestinal environment includes cells with $B p X y n 10 A$, negative selection pressure on cells without $B p X y n 10 A$ might be reduced. Compared with the membrane-bound endo-1,4- $\beta$-xylanase of other HGM xylanolytic species, free $B p X y n 10 A$ is more altruistic, especially for secondary LCX consumers.

Although intact LCX has not been considered a substrate for bifidobacteria in the human intestine [22], we found that LCX could be a substrate for the growth of bifidobacteria in the gut of people with detectable $B p X y n 10 A$. Furthermore, during cereal intervention, the number of $B$. pseudocatenulatum cells with $B p X y n 10 A$ increased in the entire $B p X y n 10 A+$ group (Fig. 6b). These findings suggest that the $B p X y n 10 A$ in faecal samples serve as an accurate biomarker to predict responders, in whom the cell numbers of $B$. pseudocatenulatum would increase under LCX-rich food intervention. Non-responders might also become responders by consuming live $B$. pseudocatenulatum with
BpXyn10A. These possibilities provide a framework that could guide intestinal bifidobacteria recalibration to gain health benefits. In particular, the selective growth of $B$. pseudocatenulatum may contribute to the alleviation of type 2 diabetes [48]. Our study paves the way for systematic manipulation of the intestinal microbiota through dietary intervention using key polysaccharide degradative enzymes as biomarkers.

\section{DATA AVAILABILITY}

Sequence data that support the findings of this study have been deposited at GenBank and Sequence Read Archive under BioProject accession no. PRJNA745059. The authors declare that all other data supporting the findings of this study are available within the article and its supplementary information files, or from the corresponding author upon request.

\section{REFERENCES}

1. Clemente JC, Ursell LK, Parfrey LW, Knight R. The impact of the gut microbiota on human health: an integrative view. Cell. 2012;148:1258-70.

2. Koropatkin NM, Cameron EA, Martens EC. How glycan metabolism shapes the human gut microbiota. Nat Rev Microbiol. 2012;10:323-35.

3. Schrezenmeir J, de Vrese M. Probiotics, prebiotics, and synbiotics-approaching a definition. Am J Clin Nutr. 2001;73:361s-4s.

4. Kaoutari AE, Armougom F, Gordon Jl, Raoult D, Henrissat B. The abundance and variety of carbohydrate-active enzymes in the human gut microbiota. Nat Rev Microbiol. 2013;11:497-504.

5. Flint HJ, Scott KP, Duncan SH, Louis $P$, Forano E. Microbial degradation of complex carbohydrates in the gut. Gut Microbes. 2012;3:289-306.

6. Shepherd ES, DeLoache WC, Pruss KM, Whitaker WR, Sonnenburg JL. An exclusive metabolic niche enables strain engraftment in the gut microbiota. Nature. 2018;557:434-8.

7. Wu M, McNulty NP, Rodionov DA, Khoroshkin MS, Griffin NW, Cheng J, et al. Genetic determinants of in vivo fitness and diet responsiveness in multiple human gut Bacteroides. Science. 2015;350:aac5992.

8. Matsuki T, Yahagi K, Mori H, Matsumoto H, Hara T, Tajima S, et al. A key genetic factor for fucosyllactose utilization affects infant gut microbiota development. Nat Commun. 2016;7:11939.

9. The Human Microbiome Project Consortium. Structure, function and diversity of the healthy human microbiome. Nature. 2012;486:207-14.

10. Matsuki T, Watanabe K, Tanaka R, Fukuda M, Oyaizu H. Distribution of bifidobacterial species in human intestinal microflora examined with 16S rRNA-genetargeted species-specific primers. Appl Environ Microbiol. 1999;65:4506-12.

11. Milani C, Lugli GA, Duranti S, Turroni F, Bottacini F, Mangifesta M, et al. Genomic encyclopedia of type strains of the genus Bifidobacterium. Appl Environ Microbiol. 2014;80:6290-302.

12. Milani C, Turroni F, Duranti S, Lugli GA, Mancabelli L, Ferrario C, et al. Genomics of the genus Bifidobacterium reveals species-specific adaptation to the glycan-rich gut environment. Appl Environ Microbiol. 2016;82:980-91.

13. Sela DA, Chapman J, Adeuya A, Kim JH, Chen F, Whitehead TR, et al. The genome sequence of Bifidobacterium longum subsp. infantis reveals adaptations for milk utilization within the infant microbiome. Proc Natl Acad Sci USA. 2008;105:18964-9.

14. Duranti S, Milani C, Lugli GA, Turroni F, Mancabelli L, Sanchez B, et al. Insights from genomes of representatives of the human gut commensal Bifidobacterium bifidum. Environ Microbiol. 2015;17:2515-31.

15. Bottacini F, Morrissey R, Esteban-Torres M, James K, van Breen J, Dikareva E, et al. Comparative genomics and genotype-phenotype associations in Bifidobacterium breve. Sci Rep. 2018;8:10633.

16. Arboleya S, Bottacini F, O'Connell-Motherway M, Ryan CA, Ross RP, van Sinderen $D$, et al. Gene-trait matching across the Bifidobacterium longum pan-genome reveals considerable diversity in carbohydrate catabolism among human infant strains. BMC Genomics. 2018;19:33.

17. Duranti S, Milani C, Lugli GA, Mancabelli L, Turroni F, Ferrario C, et al. Evaluation of genetic diversity among strains of the human gut commensal Bifidobacterium adolescentis. Sci Rep. 2016;6:23971.

18. Collins HM, Burton RA, Topping DL, Liao ML, Bacic A, Fincher GB. REVIEW: variability in fine structures of noncellulosic cell wall polysaccharides from cereal grains: potential importance in human health and nutrition. Cereal Chem J. 2010;87:272-82.

19. Chassard C, Goumy V, Leclerc M, Del'homme C, Bernalier-Donadille A. Characterization of the xylan-degrading microbial community from human faeces. FEMS Microbiol Ecol. 2007;61:121-31.

20. Rogowski A, Briggs JA, Mortimer JC, Tryfona T, Terrapon N, Lowe EC, et al. Glycan complexity dictates microbial resource allocation in the large intestine. Nat Commun. 2015;6:7481. 
21. Leth ML, Ejby M, Workman C, Ewald DA, Pedersen SS, Sternberg C, et al. Differential bacterial capture and transport preferences facilitate co-growth on dietary xylan in the human gut. Nat Microbiol. 2018;3:570-80.

22. Broekaert WF, Courtin CM, Verbeke K, Van de Wiele T, Verstraete W, Delcour JA. Prebiotic and other health-related effects of cereal-derived arabinoxylans, arabinoxylan-oligosaccharides, and xylooligosaccharides. Crit Rev Food Sci Nutr. 2011;51:178-94.

23. Ndeh D, Gilbert HJ. Biochemistry of complex glycan depolymerisation by the human gut microbiota. FEMS Microbiol Rev. 2018;42:146-64.

24. Nishijima S, Suda W, Oshima K, Kim SW, Hirose $Y$, Morita $H$, et al. The gut microbiome of healthy Japanese and its microbial and functional uniqueness. DNA Res. 2016;23:125-33.

25. Matsuki T, Watanabe K, Fujimoto J, Kado Y, Takada T, Matsumoto K, et al. Quantitative PCR with 16S rRNA-gene-targeted species-specific primers for analysis of human intestinal bifidobacteria. Appl Environ Microbiol. 2004;70:167-73.

26. Wick RR, Judd LM, Gorrie CL, Holt KE. Unicycler: resolving bacterial genome assemblies from short and long sequencing reads. PLOS Comput Biol. 2017;13: e1005595.

27. Seemann T. Prokka: rapid prokaryotic genome annotation. Bioinformatics. 2014;30:2068-9.

28. Page AJ, Cummins CA, Hunt M, Wong VK, Reuter S, Holden MT, et al. Roary: rapid large-scale prokaryote pan genome analysis. Bioinformatics. 2015;31:3691-3.

29. Yin Y, Mao X, Yang J, Chen X, Mao F, Xu Y. dbCAN: a web resource for automated carbohydrate-active enzyme annotation. Nucleic Acids Res. 2012;40:W445-51.

30. Martin M. Cutadapt removes adapter sequences from high-throughput sequencing reads. EMBnet.journal. 2011;17:10-2.

31. Kopylova E, Noé L, Touzet H. SortMeRNA: fast and accurate filtering of ribosomal RNAs in metatranscriptomic data. Bioinformatics. 2012;28:3211-7.

32. Langmead B, Salzberg SL. Fast gapped-read alignment with Bowtie 2. Nat Methods. 2012;9:357-9.

33. Liao Y, Smyth GK, Shi W. featureCounts: an efficient general purpose program for assigning sequence reads to genomic features. Bioinformatics. 2014;30:923-30.

34. Matsuki T, Watanabe K, Fujimoto J, Miyamoto $\mathrm{Y}$, Takada T, Matsumoto K, et al. Development of $16 \mathrm{~S}$ rRNA-gene-targeted group-specific primers for the detection and identification of predominant bacteria in human feces. Appl Environ Microbiol. 2002;68:5445-51.

35. Kato K, Ishida S, Tanaka M, Mitsuyama E, Xiao JZ, Odamaki T. Association between functional lactase variants and a high abundance of Bifidobacterium in the gut of healthy Japanese people. PLoS One. 2018;13:e0206189.

36. Ye J, Coulouris G, Zaretskaya I, Cutcutache I, Rozen S, Madden TL. Primer-BLAST: a tool to design target-specific primers for polymerase chain reaction. BMC Bioinformatics. 2012;13:134.

37. Bolyen E, Rideout JR, Dillon MR, Bokulich NA, Abnet CC, Al-Ghalith GA, et al. Reproducible, interactive, scalable and extensible microbiome data science using QIIME 2. Nat Biotechnol. 2019;37:852-7.

38. Verma, D., Kumar, R. \& Satyanarayana, T. Diversity in xylan-degrading prokaryotes and xylanolytic enzymes and their bioprospects. In: Microbial diversity in ecosystem sustainability and biotechnological applications: volume 2 . Soil \& agroecosystems. (eds Satyanarayana, T., Das, S. K. \& Johri, B. N.) pp 325-373 (Springer, Singapore, 2019).

39. Saito $Y$, Shigehisa A, Watanabe $Y$, Tsukuda N, Moriyama-Ohara K, Hara T, et al. Multiple transporters and glycoside hydrolases are involved in arabinoxylanderived oligosaccharide utilization in Bifidobacterium pseudocatenulatum. Appl Environ Microbiol. 2020;86:e01782-20.

40. Lagaert S, Van Campenhout S, Pollet A, Bourgois TM, Delcour JA, Courtin CM, et al. Recombinant expression and characterization of a reducing-end xylosereleasing exo-oligoxylanase from Bifidobacterium adolescentis. Appl Environ Microbiol. 2007;73:5374-7.

41. Lagaert S, Pollet A, Delcour JA, Lavigne R, Courtin CM, Volckaert G. Characterization of two $\beta$-xylosidases from Bifidobacterium adolescentis and their contribution to the hydrolysis of prebiotic xylooligosaccharides. Appl Microbiol Biotechnol. 2011;92:1179-85.

42. Kulkarni N, Shendye A, Rao M. Molecular and biotechnological aspects of xylanases. FEMS Microbiol Rev. 1999;23:411-56.

43. Kitaoka M. Bifidobacterial enzymes involved in the metabolism of human milk oligosaccharides. Adv Nutr. 2012;3:422S-429S.

44. Kazimierczak KA, Flint HJ, Scott KP. Comparative analysis of sequences flanking tet $(\mathrm{W})$ resistance genes in multiple species of gut bacteria. Antimicrob Agents Chemother. 2006;50:2632-9.

45. Miyazaki K, Hirase T, Kojima Y, Flint HJ. Medium- to large-sized xylo-oligosaccharides are responsible for xylanase induction in Prevotella bryantii B14. Microbiology. 2005;151:4121-5.
46. Despres J, Forano E, Lepercq P, Comtet-Marre S, Jubelin G, Chambon C, et al Xylan degradation by the human gut Bacteroides xylanisolvens XB1AT involves two distinct gene clusters that are linked at the transcriptional level. BMC Genomics. 2016;17:326.

47. Zhang M, Chekan JR, Dodd D, Hong PY, Radlinski L, Revindran V, et al. Xylan utilization in human gut commensal bacteria is orchestrated by unique modular organization of polysaccharide-degrading enzymes. Proc Natl Acad Sci USA. 2014;111:E3708-17.

48. Zhao L, Zhang F, Ding X, Wu G, Lam YY, Wang X, et al. Gut bacteria selectively promoted by dietary fibers alleviate type 2 diabetes. Science. 2018;359:1151-6.

49. Ohtsubo Y, Ikeda-Ohtsubo W, Nagata Y, Tsuda M. GenomeMatcher: a graphical user interface for DNA sequence comparison. BMC Bioinformatics. 2008;9:376.

50. Price MN, Dehal PS, Arkin AP. FastTree: computing large minimum evolution trees with profiles instead of a distance matrix. Mol Biol Evol. 2009;26:1641-50.

\section{ACKNOWLEDGEMENTS}

We thank Hoshitaka Matsumoto and Toshio Sasai (Yakult Central Institute) for providing technical support, and Professor Ken Kurokawa (National Institute of Genetics) for critical review of this manuscript.

\section{AUTHOR CONTRIBUTIONS}

YW and TM conceived and designed the overall study. YW, TH and YS performed genome analysis. YW, TH and YA-S performed carbohydrate availability analysis. YS generated the recombinant protein. YW performed transcriptome analysis. YW performed the co-culture experiments. YW and TM designed and managed the LCXrich food intervention trials. YW, YS, TH, NT, KY, TK and KO performed faecal manipulations. YW and TH performed $16 \mathrm{~S}$ amplicon analysis. YW performed real-time PCR analysis. YW prepared figure illustrations. YW and TM wrote the manuscript. SM supervised this work. All authors reviewed and approved the manuscript. Correspondence should be addressed to YW and TM.

\section{COMPETING INTERESTS}

This work was funded by the Yakult Central Institute. The funder provided support in the form of salaries for all authors, but did not have any additional role in the study design, data collection and analysis or preparation of the manuscript. Yakult Central Institute is the owner of a patent application based on some of the results presented, which names YW, YS, TH, YA-S and TM as inventors.

\section{ADDITIONAL INFORMATION}

Supplementary information The online version contains supplementary material available at https://doi.org/10.1038/s43705-021-00066-4.

Correspondence and requests for materials should be addressed to Yohei Watanabe or Takahiro Matsuki.

Reprints and permission information is available at http://www.nature.com/ reprints

Publisher's note Springer Nature remains neutral with regard to jurisdictional claims in published maps and institutional affiliations.

Open Access This article is licensed under a Creative Commons Attribution 4.0 International License, which permits use, sharing adaptation, distribution and reproduction in any medium or format, as long as you give appropriate credit to the original author(s) and the source, provide a link to the Creative Commons license, and indicate if changes were made. The images or other third party material in this article are included in the article's Creative Commons license, unless indicated otherwise in a credit line to the material. If material is not included in the article's Creative Commons license and your intended use is not permitted by statutory regulation or exceeds the permitted use, you will need to obtain permission directly from the copyright holder. To view a copy of this license, visit http://creativecommons.org/licenses/by/4.0/.

(c) The Author(s) 2021 